\title{
50th Growth Percentile
}

National Cancer Institute

\section{Source}

National Cancer Institute. 50th Growth Percentile. NCI Thesaurus. Code C98264.

An indication that an individual ranks in the middle of the reference population for a given attribute. 